\title{
Editorial Actio 2019
}

Leonir Lorenzetti leonirlorenzetti22@gmail.com orcid.org/0000-0001-8327-9147 Universidade Federal do Paraná (UFPR), Curitiba, Paraná, Brasil

Maria Lucia Panossian mlpanossian@utfpr.edu.br Orcid.org/0000-0001-5847-4485 Paraná (UTFPR) Curitiba, Paraná, Brasil
As universidades brasileiras são o locus de produção, sistematização e divulgação de novos conhecimentos, que contribuem para a consolidação das distintas áreas do conhecimento.

Especificamente na área de educação em Ciências e em educação Matemática observa-se um crescimento significativo de programas de PósGraduação, tanto acadêmico quanto profissional, gerando conhecimentos que precisam ser disseminados em eventos e em periódicos especializados.

Nesse sentido a revista ACTIO: Docência em Ciências, desde sua origem em 2016, tem sido considerada um importante veículo de divulgação da pesquisa em educação em Ciências e em Matemática, apresentando as seções "Articulações em Ensino de Ciências", "Educação Matemática" e "Entrevistas da Actio".

Buscando a ampliação e diversificação a revista ACTIO inova na 3a edição de 2019 ao propor o dossiê em ensino de Ciências e Matemática nos anos iniciais, buscando socializar artigos que possam contribuir para o ensino e a pesquisa neste nível de ensino, que ainda é pouco valorizado e que pode contribuir significativamente para a formação do educando.

Assim, este número contém além das seções regulares "Articulações em Ensino de Ciências" e "Educação Matemática", outras duas seções: O Dossiê Temático "Ensino de Ciências e Matemática para os anos iniciais do Ensino Fundamental" e os "Anais da III Semana das Licenciaturas da UTFPR - Câmpus Curitiba".

Na sessão Articulações em Ensino de Ciências são apresentados 4 artigos que serão explicitados a seguir de acordo com cada objetivo dos referidos autores.

Marcelo Valério e Carlos Roberto Beleti Junior no artigo "Caracterização da produção acadêmica brasileira sobre sala de aula invertida" mapeiam e caracterizam a produção acadêmica brasileira evidenciando ser está uma tendência educativa.

O artigo "Enfoque CTS e atuação de professores de ciências", escrito por Mirian Silva dos Anjos e Leandro Carbo, analisa como os professores de Ciências do Ensino Fundamental compreendem essa abordagem, identificando que as aplicações das relações CTS presentes nos currículos escolares são ainda ineficientes.

No estudo "A origem da vida: uma análise sobre a natureza da ciência em um vídeo educativo do Youtube" Marinilde Tadeu Karat e Patrícia Montanari Giraldi, utilizando o referencial de Thomas Kuhn, identificam que há uma predominância da concepção empírco-indutivista na videoaula Origem da Vida, podendo 
repercutir negativamente no ensino de Ciência.

Fechando a sessão, o artigo de Hélio da Silva Messeder Neto, "O jogo é a excalibur para o ensino de ciências? apontamentos para pensar o lúdico no ensino de conceitos e na formação do professor", problematiza concepções inatistas e apolíticas do lúdico para a formação dos professores utilizando a lenda do Rei Artur como metáfora. Os autores defendem a importância do uso mais consciente e sistemático do lúdico no ensino de Ciências.

A sessão Educação Matemática contém o texto de Bruna Corso e Flávia Dias de Souza, intitulado "O compartilhamento de ações de estágio como espaço de formação inicial para a docência". Neste artigo, as autoras apresentam os resultados de uma pesquisa fundamentada na teoria da atividade realizada com o acompanhamento de turmas de estágio curricular supervisionado. As análises revelaram a importância da coletividade e do planejamento compartilhado no processo de organização do ensino.

O dossiê temático "O ensino de Ciências e Matemática nos anos iniciais" é composto por 31 artigos apresentando distintas temáticas e abordagem teórica e metodológica, sendo provenientes de todas as regiões do Brasil, caracterizando uma amostra significativa do que tem sido produzido em ensino de Ciências e em Matemática nos anos iniciais.

O artigo "Prática de ciência e tecnologia na rede municipal de ensino de Curitiba: re-visitando a historicidade do pesquisado" de Manuelle Pereira da Costa Simeão e Luciane Ferreira Macrosky abre o dossiê, identificando as mudanças que ocorreram em cada gestão municipal e apontando a alfabetização científica e tecnológica como o traço do ensino de Ciências nos anos iniciais.

O estudo de Andrea Inês Goldschmidt, Ariadne de Freitas Leonardi, Carolina Rangel, Geovane Bernardi, Maira dos Santos Silveira e Sabrina Antunes Ferreira, denominado de "Classificação de seres vivos por alunos de anos iniciais do ensino fundamental: uma proposta de habilidades científicas", analisa uma experiência pedagógica, argumentando a importância de desenvolver as habilidades científicas dos alunos desde os anos iniciais.

"A importância da experimentação no ensino de ciências para o entendimento do ciclo da água: uma proposta para a educação infantil", pesquisa desenvolvida por Ana Carolina Ferreira Machado, Verônica Soares dos Santos e Elvanise Maria Rizzatti destaca a importância da experimentação desde a Educação Infantil como forma de contribuir para a formação integral e para a promoção da alfabetização científica.

O artigo de Bruna Cristina Carvalho Gomes e Dulcimeire Aparecida Volante Zanon, "A educação através da ciência, tecnologia e sociedade (CTS) para os anos iniciais do ensino fundamental: a terra e o universo em foco", analisa as implicações de uma proposta de ensino, evidenciando suas contribuições para a alfabetização científica e a alfabetização materna, destacando a importância da atuação do professor.

Maria Alina Oliveira Alencar de Araújo e Raquel Crosara Maia Leite no artigo "Alfabetização científica nos anos iniciais do ensino fundamental: o que nos dizem os documentos oficiais" investigam as concepções de alfabetização cientifica, apontando ambiguidades nos textos oficiais em um contexto atual de cobranças 
externas e internas à escola, por meio de avaliações de larga escala.

A pesquisa de Márcia Márcia Priscilla Castro Lana e Fabio Augusto Rodrigues e Silva, "O ensino de ciências nos nãos iniciais com o aporte da literatura infantil de Monteiro Lobato", descreve e analisa o processo de ensino e de aprendizagem propiciando por uma atividade que utilizou a literatura infantil para trabalhar conceitos científicos.

O artigo de Marcelo Souza Motta, Stephanie Johansen Longo Basso e Marco Aurélio Kalinke intitulado "Mapeamento sistemático das pesquisas realizadas nos programas de mestrado profissional que versam sobre a aprendizagem matemática na educação infantil" como o próprio título indica realiza o mapeamento das pesquisas no recorte temporal de 2013 a 2018. Após seleção entre 84 artigos, os autores estudam 12 pesquisas e indicam a diversidade metodológica das pesquisas e a falta de destaque sobre os produtos educacionais derivados.

"O ensino de química para as séries iniciais: análise de correspondência entre desenho animado e experimentação adotados como estratégia no curso de pedagogia para o ensino de ciências", elaborado por Lucicleia Pereira da Silva, Débora da Cruz Arruda, Ligia Amaral Filgueiras e Admilson Alcântara da Silva, avalia a percepção de pedagogos em formação inicial sobre a correlação entre o uso de desenho animado e experimentação enquanto estratégia de ensino.

Analisar as contribuições do uso de recursos pedagógicos lúdico-interativos abrangendo o tema câncer de pele para a promoção da Alfabetização Científica caracterizou a pesquisa 'Contribuições de recursos pedagógicos sobre câncer de pele para alfabetização científica no ensino fundamental' escrita por Patricia Marega, Marcelo Leite da Veiga e Maria Rosa Chitolina.

O estudo de Emerson Nunes da Costa Gonçalves, Mauricio Compiani e Carlos Alberto de Oliveira Magalhães Júnior, "O ensino de ciências e a formação continuada de professores alfabetizadores: reconhecendo o campo de pesquisa", identifica e analisa pesquisas, teses e dissertações que discutem a educação continuada de professores alfabetizadores como mediadores do conhecimento científico no Ciclo de Alfabetização.

Silmara Alessi Guebur Roehrig e Marcos Vinicius Faian Santos, no artigo "A física nos anos iniciais da educação básica: uma análise dos documentos curriculares adotados pela rede municipal de Curtitiba/PR", analisam que a Física constitui-se em uma importante dimensão para a introdução às Ciências da Natureza nos anos inicias, e precisa ser abordada em conjunto com os conhecimentos das demais áreas que pertencem a essa ciência.

O artigo "Ação social responsável: práticas de letramento científico e matemático nos anos iniciais do ensino fundamental", de Adriano Santos Mesquita foi traduzido para o francês. Usando a narrativa autobiográfica o texto apresenta aspectos relativos à ação social responsável com uma turma de quinto ano do Ensino Fundamental, na cidade de Belém do Pará. Os resultados destacam o potencial de situações de letramento científico e matemático em sala de aula.

A pesquisa de Adana Teixeira Gonzaga, Ana Caroline Lima de Souza, Rafael Gonçalves Brito, Caroline Barroncas Oliveira e Mônica Oliveira Costa denominada "Os espaços não formais em cena: uma carta àqueles que defendem a educação em ciências e a Amazônia" problematiza como o fechamento de espaços não 
formais atinge a educação científica.

No artigo "Ensino de ciências por investigação: contribuições da leitura para a alfabetização científica nos anos iniciais", os autores Tamiris de Almeida Silva, Silvana Paulina de Souza e Elton Casado Fireman argumentam que a leitura de textos permite a inclusão dos estudantes na cultura científica por meio da aprendizagem de conceitos, ampliação de vocabulário, compreensão da natureza das Ciências e formação de cidadãos críticos e conhecedores de seus direitos e deveres na sociedade.

Suélen Rita Andrade Machado e Lucieli Trivizoli através da pesquisa denominada "História da matemática na formação inicial de professores dos anos iniciais" fazem um levantamento de teses e dissertações sobre esta temática. Reconhecem que há poucos trabalhos sobre o assunto e que os mesmos são caracterizados pela diversidade de procedimentos teóricos e metodológicos adotados, mas ainda há necessidade de aumento da produção nessa área.

A pesquisa de Graziele Scalfi, Amanda Cristina Teagno Lopes Marques, Cynthia Iszlaji, Barbara Milan, Jessica Norberto Rocha e Martha Marandino intitulada "Análise do processo de alfabetização científica em crianças em espaços de educação não formal e divulgação da ciência" analisa a aplicabilidade da ferramenta teórico-metodológica de Indicadores de Alfabetização Científica para o estudo e a avaliação de ações educativas e de divulgação científica para crianças.

O artigo "Possibilidades e desafios para formação permanente de educadores dos anos iniciais: uma revisão de literatura", elaborado por Sabrina Gonçalves Marques e Cristiane Muenchen, investiga elementos teóricos e metodológicos que contribuem para construção de processos formativos de educadores atuantes nos anos iniciais do Ensino Fundamental.

"Jogos matemáticos e a formação de professores indígenas nos anos iniciais do ensino fundamental", o artigo de Maria Simone Jacomini Novak, Maria Christine Berdusco Menezes e Evania da Silva Novak Franco enfatiza a etnomatemática e a relação entre conhecimentos matemáticos indígenas e universais. Por meio de oficinas de jogos desenvolvidos na universidade e em escolas indígenas reconhecem o que dá sentido ao conhecimento matemático na brincadeira.

No artigo "A percepção de estudantes dos anos iniciais do ensino fundamental sobre a vivência da pesquisa a partir de uma unidade de aprendizagem" as autoras Lorita Aparecida Veloso Galle, Mônica da Silva Gallon e Alessandra Tatiana Krause Silveira fornecem indicativos para assegurar a relevância de propostas metodológicas que valorizem os conhecimentos dos estudantes e seu protagonismo, bem como considerem os seus interesses expressos em perguntas.

Os resultados de uma pesquisa sobre "Estrutura multiplicativa de números naturais em manuais didáticos dos anos iniciais do ensino fundamental", é o tema da pesquisa de Marli Schmitt Zanella, João Marcos de Araújo Krachinscki e Idelmar André Zanella. A teoria dos campos conceituais de Gerard Vergnaud é o fundamento para identificar a multiplicação como soma de parcelas iguais, disposição retangular, combinação de possibilidades, repartição igualitária e quantos cabem, mas ainda destaca-se a necessidade de abordar situações 
diferenciadas, articuladas com a divisão, em diferentes contextos e graus de dificuldades.

Hanslivian Correia Cruz Bonfim e Orliney Maciel Guimarães no artigo "Compreensões de professoras dos anos iniciais sobre os objetivos do ensino de ciências, da alfabetização científica e tecnológica e das relações entre ciência, tecnologia e sociedade no ensino fundamental" constaram que as professoras compreendem que o ensino de Ciências possibilita a compreensão de mundo, reconhecem as relações CTS de forma superficial e desconhecem o termo alfabetização científica e tecnológica.

O artigo "Análise do uso de objetos materiais mediacionais em uma aula investigativa de ciência de cunho sociocientífico nos anos iniciais do ensino fundamental", escrito por Leandro da Silva Barcellos e Geide Rosa Coelho, analisa a mediação pedagógica do professor ao implementar uma sequência de ensino que abordou o tema interação radiação ultravioleta-corpo humano.

O texto "Ensino de ciências e matemática nos anos iniciais: uma análise de teses da área de ensino", de Alana Rodrigues Rigão e Greice Scremin, se propõe a analisar 18 teses sobre a temática publicadas entre 2013 e 2017. Para tanto, usam três categorias definidas a priori: a) conhecimento específico; b) aspectos didáticos e c) perspectivas de formação docente, sendo esta última categoria pouco evidenciada nas pesquisas analisadas.

O estudo de lago Vilaça de Carvalho, Brenda Iolanda Silva do Nascimento, Stella Almeida e Fernanda Antunes Gomes da Costa denominado "Caminhos descoloniais possíveis no ensino de ciências das séries iniciais: um diálogo com a obra 'meu crespo é de rainha"' objetiva pensar a aula de Ciências a partir da perspectiva orientada pela Lei 10.639/03, em que aspectos da História e da Cultura Africana e Afro-brasileira devem ser abordados em todo currículo escolar.

Analisar como as crianças interpretam e integram os saberes de Ciências da Natureza, por meio de suas próprias práticas é o objetivo do artigo "Ensino de ciência e educação infantil: um estudo pautado na reprodução interpretativa e cultura da infância" que foi desenvolvido por Thayse Geane Iglesias e Camila Silveira.

O artigo "Alfabetização científica no ensino de ciências nos anos iniciais do ensino fundamental: percepções de professores da rede municipal de ensino de Curitiba", escrito por Lucimara Fabricio e Alisson Antonio Martins, aponta para uma necessidade de se repensar os objetivos e as práticas desenvolvidas no ensino de Ciências, para que seja possível o desenvolvimento de um processo de alfabetização científica e, assim, sejam preenchidas as lacunas que existem na compreensão dessa abordagem.

O texto "Leitura e ensino de ciências nos anos iniciais: análise das pesquisas do ENPEC (1997-2017)" de Luciana Sedano, Caroline Batista Silva de Souza e Frédéric André Robert Vaillant destaca o baixo número de trabalhos publicados com a temática leitura e ensino de Ciências em todas as edições do evento e, entre os analisados, pouca correspondência nas relações entre leitura e ensino de Ciências defendidas.

Articulando História da Matemática e Etnomatemática em uma proposta de ensino para alunos do 50 ano do Ensino Fundamental, a pesquisa de Juliana Batista Pereira dos Santos e Isabel Cristina Machado de Lara é intitulada "O 
algoritmo da multiplicação: possibilidades de diferentes formas de matematizar" Os resultados da análise evidenciam as potencialidades da proposta de ensino que possibilitou aos estudantes outras formas de matematizar através de jogos de linguagem com regras específicas, bem como reflexões sobre o jogo de linguagem da Matemática Escolar.

Analisar possibilidades e desafios de ensinar e aprender o conceito de número nos anos iniciais, é o objetivo do texto "Ensinar e aprender o conceito de número nos anos iniciais: o clube de matemática", de Anemari Roesler Luersen Vieira Lopes, Ana Luiza Golin, Camila Porto Giacomelli e Maiara Luisa Klein. As autoras que se baseiam na teoria da atividade e na atividade orientadora de ensino, realizam suas pesquisas no Clube de Matemática e destacam a importância da interação com a professora regente, a intencionalidade na organização do ensino e o material sensorial adequado aos alunos.

Marzane Garvão e lône Inês Pinsson Slongo no artigo "O ensino de ciências no currículo oficial dos anos iniciais: uma leitura da sua história" apontam a recente presença da educação científica nos anos iniciais, com destaque para as modificações que suas concepções e finalidades têm sofrido, notadamente, nas duas últimas décadas.

O artigo que encerra este dossiê temático é "Conhecimento especializado de futuros professores da educação infantil e dos anos iniciais quanto às dificuldades de aprendizagem de alunos cegos e videntes sobre paralelismo" de Silvania Couto e Miguel Ribeiro. Os autores destacam a importância do conhecimento especializado do conteúdo pelos professores e destacam que identificar o paralelismo não significa saber representá-lo.

A III Semana das Licenciaturas é um evento promovido por docentes e discentes das licenciaturas da Universidade Tecnológica Federal do Paraná Câmpus Curitiba. Neste evento são apresentados os estudos e pesquisas derivados de trabalhos de conclusão de curso, projetos de iniciação científica, resultados do Programa Institucional de Bolsas de Iniciação à Docência (PIBID) e do Programa Residência Pedagógica, produtos educacionais das pesquisas de mestrado profissional entre outros. O evento conta com palestras, mini-cursos, oficinas, comunicações orais e pôsters, e integra estudantes da graduação, da pós-graduação, professores do ensino básico e superior. Esta edição da revista incorpora os anais deste evento realizado em outubro de 2019.

Almejamos que os artigos publicados nesta edição possam de alguma forma contribuir para o desenvolvimento profissional e com a pesquisa em educação em Ciências e em Matemática. 
Recebido:15 dez. 2019

Aprovado:20 dez. 2019

DOI:10.3895/actio.v3n4.11488

Como citar:

LORENZETTI, L.; PANOSSIAN, M. L. Editorial Actio 2019. ACTIO, Curitiba, v. 4, n. 3, p. 722-728,

set./dez. 2019. Disponível em: https://periodicos.utfpr.edu.br/actio. Acesso em: XXX

Correspondência:

Leonir Lorenzetti

Rua José Cadilhe, 804, ap. 52H - Água Verde, Curitiba, Paraná, Brasil

Maria Lucia Panossian

Rua Eugênio José de Souza, 993, ap. 401 - Água Verde, Curitiba, Paraná, Brasil.

Direito autoral: Este artigo está licenciado sob os termos da Licença CreativeCommons-Atribuição 4.0

Internacional.

(c) (1) 